\title{
Peer Assisted Learning in Clinical Education: Literature Review
}

Jolene M. Henning, EdD, ATC, LAT*; Thomas G. Weidner, PhD, ATC, LAT†; Melissa C. Marty, MS, ATC, LAT*

*The University of North Carolina at Greensboro, Greensboro, NC; †Ball State University, Muncie, IN

Objective: To examine the occurrence, benefits, and preferences for peer assisted learning (PAL) in medical and allied health clinical education, and to identify areas in athletic training which need further research.

Data Sources: Using relevant terms, five databases were searched for the period 1980-2006 regarding literature on the use of PAL in medical and allied health education programs.

Data Synthesis: We reviewed over 40 articles on the use of PAL in nursing, physical therapy, occupational therapy, medicine, athletic training, and higher education. It is apparent that PAL is a commonly used educational strategy that offers mutual benefits to participating students.
Conclusions/Recommendations: Research is warranted regarding the preferences for and occurrence and benefits of planned and unplanned PAL from the perspective of program administrators, clinical instructors, and students. These multiple perspectives will allow for a more complete understanding of PAL in athletic training clinical education, laying the groundwork for future studies comparing student learning outcomes in ATEPs with planned PAL to those with unplanned PAL.

Key Words: Peer Teaching, Peer Learning, Peer Mentoring, Peer Assessment, Peer Leadership
$\mathrm{M}$ edical and allied health education programs, in particular nursing, athletic training, and physical therapy, share common traits in the structure of clinical education. Each require clinical experiences for students that provide valuable hands-on patient care in real life situations. These professional preparation programs also all utilize clinical instructors who must expertly balance patient care with clinical instruction of students. Athletic training clinical instructors, however, experience additional strain as they adhere to new accreditation standards. In addition to more stringent direct clinical supervision requirements, athletic training students are now limited in the amount of hours they can spend on a weekly basis in clinical experiences. ${ }^{1}$ These standards challenge Athletic Training Education Programs (ATEPs) and their clinical instructors to truly maximize their students' clinical learning opportunities. Creative strategies for fostering quality clinical

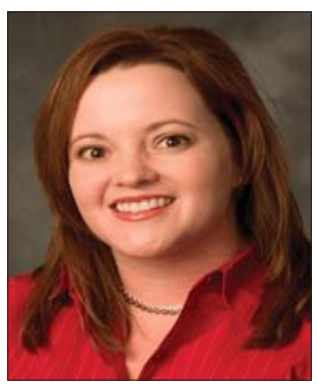

Dr. Henning is an Asst. Professor and directs the Entry-level Master's ATEP at UNC-Greensboro. jmhenni2@uncg.edu Dr. Weidner is a Professor and Director of Ball State University's ATEP.

tweidner@bsu.edu Ms. Marty is a PhD student at UNCGreensboro. mcmarty@uncg.edu education with these constraints will involve looking beyond clinical instructors for teaching, providing feedback, and mentoring students. To this end, athletic training educators and researchers have suggested that peer assisted learning (PAL) be implemented in clinical education in order to supplement and augment the role of the clinical instructor. ${ }^{2}$

PAL can be intentionally planned, but regularly occurs unintentionally or incidentally (i.e., students assisting one another in learning clinical skills). ${ }^{3,4}$ Studies over the past two decades in nursing, physical therapy and medicine document the planned and unplanned use of PAL as well as its benefits in laboratory and clinical education. ${ }^{5-9}$ Research has also been conducted in these fields examining students' preferences for PAL compared to other forms of clinical instruction (e.g., expert led instruction). 2, 7, 10, 11 However, research regarding PAL in athletic training clinical education is sparse. ${ }^{2,12}$ The purpose of this literature review is to examine the occurrence, benefits, and preferences for PAL in medical and allied health clinical education, and to identify areas in athletic training which need further research. We examined several databases (CINAHL, Sport Discus, MEDLINE, ERIC, and EBSCO) from 1980-2006 for literature on the use of PAL in medical and allied health education programs. The following key words guided our searches: peer teaching, peer learning, peer assessment, peer leadership, peer tutoring, and peer mentoring. Over 40 articles regarding the use of various forms of PAL in nursing, physical therapy, medicine, and athletic training were identified. In some cases, these disciplines do not have published research regarding 
certain types of PAL (e.g., peer leadership) therefore suggesting that further research may be needed in those areas.

\section{Operational Definition of PAL}

PAL is an umbrella term encompassing a variety of cooperative and collaborative educational strategies, including peer teaching, peer learning, peer assessment, peer mentoring, and peer leadership. ${ }^{5,6,8,9,13-17}$ Operational definitions of each specific type of PAL are explained in Table 1. A peer is a student at the same or different academic or experience level. ${ }^{17}$ Learning can be defined as "to gain knowledge, understanding, or skill through instruction or experience." ${ }^{17}$ Therefore, PAL is the act or process of gaining knowledge, understanding, or skill from students that are either at different or equivalent academic or experiential levels. ${ }^{2}$

Table 1. Operational Definitions of Types of PAL

\begin{tabular}{ll}
\hline PAL Activity & Operational Definition \\
\hline $\begin{array}{l}\text { Peer teaching and } \\
\text { learning }\end{array}$ & $\begin{array}{l}\text { Student instructing another } \\
\text { student(s) }\end{array}$ \\
$\begin{array}{l}\text { Peer assessment and } \\
\text { feedback }\end{array}$ & $\begin{array}{l}\text { Students evaluating other students' } \\
\text { products or outcomes of learning }\end{array}$ \\
Peer mentoring & $\begin{array}{l}\text { Student relationship with another } \\
\text { student(s) that fosters nurturing, } \\
\text { sharing, encouragement, and } \\
\text { support }\end{array}$ \\
& $\begin{array}{l}\text { Students leading other students } \\
\text { independently from the clinical } \\
\text { instructor }\end{array}$ \\
\hline
\end{tabular}

\section{Occurrence of PAL Strategies}

This section will examine the occurrence of planned and unplanned PAL in both laboratory and clinical settings in allied health education settings, as well as identify areas of further research in athletic training clinical education.

\section{Peer Teaching and Learning}

Peer teaching and learning are often examined simultaneously in the literature because the very act of peer teaching implies that there is also a peer in the role of a learner. Furthermore, the roles of teacher and learner are often fluid, with students changing roles throughout the teaching and learning process. ${ }^{18}$

Multiple forms of planned peer teaching and learning take place in medical, nursing, and physical therapy clinical education (in both the laboratory and clinical settings). Peer teaching in medical schools often occurs in the laboratory setting as reciprocal peer teaching, in which students alternate between the roles of peer teacher and peer learner. ${ }^{18}$ In this situation, students taught each other during a gross anatomy lab in groups of six to seven students. Medical schools have also used upper level students (under supervision) to teach clinical skills in the laboratory setting. ${ }^{7}$

Planned peer teaching is also widely used in nursing clinical settings where more experienced students are paired with less experienced students to facilitate teaching and learning of basic clinical skills. ${ }^{3,6,10,15,19}$ Planned peer teaching has ranged from teaching individual psychomotor skills ${ }^{10}$ to assigning a peer teacher to a nursing student during the first clinical rotation. ${ }^{6}$ Unplanned or incidental peer teaching occurs in the nursing clinical setting and has been referred to as the "hidden curriculum." ${ }^{3}$ Specifically, 50\% of nursing students reported learning most of their practical skills from their peers. ${ }^{3}$ Similarly, another nursing education study reported that $27 \%$ of nursing students felt that they were taught the most by other nursing students during their clinical education. ${ }^{20}$

Several studies in physical therapy indicate that clinical environments are conducive to incidental peer teaching and learning. ${ }^{11,21,22}$ For example, physical therapy clinical instructors have reported that simply changing the student to clinical instructor ratio from $1: 1$ to $2: 1$ or $3: 1$ fostered incidental peer teaching and learning. ${ }^{11,21-23}$ Students in these studies were placed with peers during clinical education without specific learning objectives. The purposes of the studies were to document benefits from unplanned peer learning, ${ }^{11,21-23}$ advantages of a clinical site that fosters peer learning, ${ }^{11}$ and patient opinions of treatment given by students in peer learning situations. ${ }^{23}$ Specifically, one study found that students placed in a collaborative clinical placement with a $2: 1$ student to clinical instructor ratio scored higher on clinical competence evaluation forms. ${ }^{21}$ In regards to factors affecting peer learning, Nemshick and Ladyshewsky ${ }^{11}$ reported that students felt having a peer at the same clinical site created a comfortable and safe environment for learning as well as the opportunity to share ideas and practice clinical skills. This same study indicated that some clinical supervisors also benefitted from having multiple students because it increased the opportunity to delegate tasks. ${ }^{11}$ Another study ${ }^{23}$ informally surveyed patients who treated in a physical therapy clinic with a 3 students to 1 therapist ratio and found that patients were pleased with the increased amount of time and attention provided by the students.

Planned PAL has been suggested for use in athletic training clinical education. ${ }^{2}$ In addition, incidental peer teaching and learning is often anecdotally observed in the athletic training clinical setting. However, the frequency and effectiveness of planned or unplanned PAL in athletic training laboratory and clinical settings is unknown.

\section{Peer Assessment and Feedback}

Planned peer assessment and feedback is frequently used in nursing and medicine clinical education. For example, nursing students sometimes provide one another with constructive criticism regarding their communication skills, clinical problem solving skills, and overall clinical performance. ${ }^{15,24,25}$ While there are contrasting opinions regarding the validity and reliability of peer assessment and feedback in medical education, it has been implemented to assess students' psychomotor skills, interviewing 
skills, and professionalism. ${ }^{26-28}$

A recent study regarding $\mathrm{PAL}$ in athletic training examined peer assessment and feedback as part of a peer teaching/tutoring program in athletic training clinical education. ${ }^{12}$ The students either attended review sessions of orthopedic evaluation psychomotor skills led by a clinical instructor, or a peer tutor. Pretest-posttest scores indicated that students' performance of the psychomotor skills improved in both groups, but there were no significant differences in the posttest scores between groups. Athletic training peer assessment and feedback has also been incorporated into assessment of videotaped orthopedic evaluation simulations used in laboratory education and may improve critical thinking skills. ${ }^{29}$ Students first watched videos of their peers performing orthopedic evaluations in the clinical setting and then provided a critique of how the physical exam could have been improved. ${ }^{29}$

Peer assessment can be used as a benchmark as athletic training students progress through their clinical education. ${ }^{30}$ In fact, several athletic training clinical skills textbooks suggest that peer assessment be a planned component of skill acquisition. However, it remains unclear whether ATEPs are integrating planned or unplanned peer assessment in clinical education. Furthermore it is unclear whether peer assessment is an effective means of enhancing athletic training students' clinical skill acquisition.

\section{Peer Mentoring}

Mentoring is typically described as a long-term professional relationship between two individuals, one as the mentor and the other as the protégé, for the purpose of fostering professional development. ${ }^{31}$ Traditionally, the mentor is more experienced than the protégé. $^{31}$ However, recent research in nursing clinical education suggests that students may engage in short-term mentoring relationships with their peers. ${ }^{8}$ Peer mentoring can be described as a supportive or nurturing relationship between two students of differing academic or experience levels within the professional program (e.g., an upper level student mentoring a lower level student). ${ }^{8,16}$ Peer mentoring focuses more on emotional support and encouragement, rather than on peer teaching and learning. ${ }^{6,9}$ The majority of research we reviewed on peer mentoring is in the nursing and athletic training professions.

Peer mentoring is also used to assist with the professional socialization process whereby students acquire the norms, values, knowledge, and skills to function in a particular role. ${ }^{32}$ For instance, in nursing clinical education advanced students have been intentionally paired with beginning students so that they can model professional behaviors, teach professional values (e.g., collegiality), and foster personal and professional growth. ${ }^{5,8,16}$ Nursing protégés viewed their peer mentors as role models and as sources of emotional support. ${ }^{8}$ Peer mentoring has also been intentionally implemented in nursing clinical education to develop mentoring skills in future nursing professionals. ${ }^{6}$ As nursing clinical instructors have multiple demands on their time, peer mentoring has been used to supplement traditional clinical instructor-student mentor relationships. ${ }^{5}$
Student perspectives regarding mentoring have been examined in athletic training professional socialization. ${ }^{31}$ In a study examining mentors, the majority of athletic training students reported that their mentor was a current practicing athletic trainer (e.g., head athletic trainer) while a small percentage felt that a peer could be a mentor. This suggests that athletic training students may assist one another in the professional socialization process. ${ }^{31}$ In addition, athletic training students identified the roles of peer mentors as consistent with those described previously in the nursing peer mentoring studies (e.g., emotional support, role modeling, giving advice). ${ }^{31}$ Also, previous research indicates that athletic training students often seek advice from their peers while in the clinical setting. ${ }^{2}$

These studies suggest that peer mentoring occurs in athletic training clinical education. However, it is unclear whether peer mentoring happens naturally (i.e., unplanned) or if it is a planned component of athletic training clinical education. In addition, research is needed to determine to what extent a peer effectively fulfills the role of a mentor in either planned or unplanned situations.

\section{Peer Leadership}

Peer leadership has been reported in nursing clinical education as a planned component of clinical education. Nursing educators and researchers report that nursing students have few opportunities to develop and practice leadership skills prior to entering the workforce. ${ }^{14}$ Therefore, nursing educators have purposely planned clinical experiences to foster students' opportunities to practice leadership skills. ${ }^{13,14}$ For example, a nursing student may be assigned as the team leader in clinical rotation for one day. ${ }^{13}$ In this leadership role the student assumes responsibility for coordinating patient coverage on the ward, along with associated documentation and patient chart updates. ${ }^{13}$ Students felt the experience as peer leader was valuable to their professional growth. ${ }^{13}$

Anecdotally, it is not an uncommon practice in athletic training clinical education to assign a more experienced athletic training student to the role of "head" or "lead" athletic training student. With this designation comes an implied responsibility of delegating tasks, giving directions, and taking the lead in solving clinical problems. Unfortunately, there is no research regarding peer leadership in athletic training. Therefore, research is needed to determine to what extent peer leadership is a planned (or unplanned) component of athletic training clinical education.

\section{Summary of Research Needed Regarding the Occurrence of PAL} in Athletic Training

Athletic training educators often anecdotally observe that PAL occurs naturally. In fact, some PAL research in athletic training does suggest that unplanned or incidental PAL occurs in the clinical education setting. ${ }^{2,4}$ However, the following research questions warrant further investigation:

1. To what extent does PAL occur as either a planned (intentional) or an unplanned (incidental) component of athletic 
training clinical education?

2. Does PAL occur more frequently or more effectively in either the laboratory or clinical setting?

3. Is PAL more conducive in different types of clinical settings (e.g., collegiate, high school, or rehabilitation setting)?

\section{Benefits of PAL Strategies}

It is generally thought that students experience mutual benefits whether they are on the giving or receiving end of PAL interactions. This section will overview multiple benefits of peer teaching and learning, peer assessment and feedback, peer mentoring, and peer leadership as substantiated in the medical, nursing, physical therapy, and to some extent, the athletic training literature. As well, areas for further research in athletic training clinical education regarding the benefits of PAL will be identified.

\section{Peer Teaching and Learning}

The underlying premise of peer teaching is that the student who teaches a peer gains a deeper understanding in the subject matter or clinical skill, because the process of teaching inherently requires a deepening of knowledge. ${ }^{33}$ Peer teaching is a type of cooperative learning in which both "teacher" and "learner" mutually benefit from their interactions. ${ }^{12,18,19,33}$

Medical students serving as peer teachers in a laboratory setting reported improved study habits and better attitudes towards the subject matter. ${ }^{18}$ The peer teachers also benefited from a review of material, improved their communication skills, and increased their self-confidence. ${ }^{34}$ Medical students serving as Clinical Skills Teaching Assistants (CSTA) reported enjoying their roles as peer teachers and becoming more comfortable giving and receiving feedback on clinical performance. ${ }^{7}$ Learners cited benefits as well, stating that PAL experiences reinforced self-confidence, enhanced clinical skills and acquisition of new information, reinforced previously learned information and techniques, and improved ability to accept feedback. ${ }^{7}$ Learners reported feeling comfortable with their peer teachers and thought they provided useful and non-threatening feedback. ${ }^{6,34}$

Benefits of peer teaching and learning have also been reported in nursing clinical education. Nursing students involved in peer teaching and learning have improved their psychomotor test scores and improved their overall clinical knowledge. ${ }^{10}$ In addition, nursing students who collaborated in the clinical setting improved their critical thinking skills and depended less on their clinical instructor. $^{14}$ As well, lower level nursing students learned to appreciate setting priorities and making decisions when paired with upper level students who cared for many patients at one time. ${ }^{14}$ Patient care and patient education skills improved with peer teaching in nursing, ${ }^{19}$ and peer teachers have reported that developing their clinical instructional skills was a valuable experience. ${ }^{5,6}$ Another study concluded that nursing students experienced more stress when instructors were present. This was true especially when students were faced with new clinical situations as well as when the clinical instructor was just present to simply observe clinical performance (not to provide a formal evaluation) ${ }^{35}$ Practicing first with a peer made performing a skill in front of the instructor less stressful. Peer learners also felt that the experiences with their peer teachers enriched their knowledge and helped them to overcome apprehensions and fears during clinical experiences. ${ }^{6}$

Various studies have explored the benefits of peer teaching in physical therapy clinical education. Physical therapy students reported that they enjoyed problem-solving with their peers and felt more responsible and independent during their clinical experiences. ${ }^{23}$ These same students reported that the experience mimicked the collaboration that occurs during true clinical practice and led them to be less dependent on their clinical instructor. ${ }^{23}$

Other studies in physical therapy clinical education examined the benefits for students working in a clinical environment with a $2: 1$ student to clinical instructor ratio. Researchers concluded that these students are often faced with clinical challenges, and that a peer can assist them in the problem-solving process, in turn facilitating critical thinking and reasoning skills. ${ }^{36}$ In addition, physical therapy students participating in a 2:1 student-clinical instructor ratio score significantly higher in all measures of clinical competence compared to those students in a $1: 1$ student-clinical instructor ratio. ${ }^{21}$ Physical therapy students have also indicated that in a 2:1 ratio they were able to practice their skills with each other and engage in joint problem-solving. ${ }^{22}$ These students also indicated that the presence of another student helped in reducing their level of anxiety when entering a new clinical education setting. ${ }^{22}$

In another study of the 2:1 clinical education model in physical therapy, students felt that having a peer present created a positive, comfortable, and secure environment for learning in the clinical setting. ${ }^{11}$ Social communication between peers was both supportive and enjoyable. The students stated that because a peer was present they had more opportunities to share ideas and practice clinical techniques, resulting in increased opportunities for collaborating, and sharing knowledge and skills with each other. ${ }^{11}$

Two recent studies on PAL in athletic training clinical education indicated that students were less anxious and more self-confident when practicing clinical skills with their peers., ${ }^{2,12}$ Furthermore, athletic training students participating in a structured peer teaching/tutoring program improved their orthopedic assessment skills and enhanced collaboration with their peers. ${ }^{12}$ Future research in athletic training clinical education should examine the benefits of peer teaching and learning in various curricular content areas (e.g., therapeutic modalities, general medical conditions) to determine if students benefit more from peer teaching and learning in particular content than in others. In addition, exploring the benefits of peer teaching and learning during clinical experiences in different settings (i.e., collegiate, high school, and rehabilitation settings) would be helpful to determine if students seem to benefit more in particular settings than in others. 


\section{Peer Assessment and Feedback}

Educators have suggested that students may benefit from peer assessment and feedback experiences because it would give them valuable insight into the assessment process. ${ }^{37}$ Peer assessment and feedback is often purposely incorporated into clinical education to give students experience in giving and receiving constructive criticism. ${ }^{38}$ Nursing educators and researchers reported that introducing concepts of peer assessment and feedback into clinical education promoted interdependence and socialized students to seek constructive criticism and collegial interactions in future professional practice. $^{24,38}$ Nursing students also reported improvements in the ability to self-identify areas for improvement as a result of feedback received from their peers. ${ }^{24,25}$ In contrast to nursing clinical education, research in physical therapy suggests that students perceived that the feedback received from their peers was inadequate and lacked sufficient detail. ${ }^{39}$

Educators and researchers in athletic training have begun to explore the benefits of peer assessment and feedback in clinical education. Recent research in athletic training indicated that peer assessment and feedback may be most appropriate relative to individual psychomotor competencies rather than to complex clinical proficiencies. ${ }^{12}$ As previously mentioned, athletic training students appeared to benefit from peer feedback received in teaching/tutoring sessions as demonstrated by improved scores on orthopedic clinical skill tests. ${ }^{12}$ While clinical skills textbooks in athletic training promote the use of peer assessment and feedback, it is unclear whether this form of evaluation is a reliable and valid method to enhance skill acquisition in athletic training students. ${ }^{40}$, 41 Therefore, research is needed to determine the reliability and validity of peer assessment and feedback when compared to that provided by clinical instructors.

\section{Peer Mentoring}

Peer mentoring is thought to benefit both the mentor and the protégé. ${ }^{9}$ Nursing students in the role of peer mentor experienced a sense of personal growth and development, and joy and satisfaction in helping others. ${ }^{9}$ Peer mentors also developed organizational skills, were more self-reflective of their clinical practice, and sometimes realized they wanted to mentor/teach in the future. $^{3,9}$ Nursing students in the role of protégé also benefitted from the relationship experiencing less anxiety, increased self confidence, and increased comfort in the clinical environment. $3,8,9$,

There is a lack of research on the benefits of peer mentoring in athletic training clinical education. Previous research indicates that students often seek advice from their peers while in the clinical setting. ${ }^{2}$ However, it is unclear what type of advice they sought from peers (e.g., patient care advice versus career planning). Further research is necessary to determine the benefits of peer mentoring relationships among athletic training students.

\section{Peer Leadership}

The benefits of peer leadership have been examined primarily in the nursing literature. Nursing students in the role of peer leader reported learning how to prioritize patient care and how to multitask. ${ }^{14}$ Through balancing patient care and administrative responsibilities, peer leaders developed organizational skills and a more realistic understanding of their roles as health care providers. ${ }^{14}$ Moreover, peer leaders reported an increased sense of self-awareness regarding their clinical skills and an increased self-confidence in their ability to supervise a colleague. ${ }^{15}$ In addition to benefitting personally, peer leaders may create benefits for their clinical supervisors. ${ }^{13}$ Clinical nursing faculty indicated that using peer leaders made it easier for faculty to supervise multiple students and provide more time for clinical teaching. ${ }^{13}$

Little is known about the benefits of peer leadership in athletic training clinical education. Some research suggests that pairing upper and lower level athletic training students together during clinical experiences may foster leadership opportunities. ${ }^{4}$ Research is needed to determine if leadership experiences during professional preparation results in better leadership skills upon entering the workforce as clinicians and/or clinical instructors.

Summary of Research Needed Regarding the Benefits of PAL in Athletic Training

The benefits of PAL in athletic training have begun to be explored. Previous research has found that athletic training students perceive that they benefit from some forms of PAL (e.g., peer teaching) but it is unclear whether they benefit from other forms of PAL such as peer mentoring and peer leadership. ${ }^{2,12}$ Therefore, investigating the following research questions will assist athletic training faculty in developing more effective PAL programs in both the laboratory and clinical settings:

1. What are the educational and psychosocial benefits of peer teaching, peer learning, peer assessment, peer mentoring and peer leadership in athletic training?

2. Do athletic training students benefit more from the different types of PAL in the laboratory versus clinical settings?

\section{Preferences for PAL}

Few studies directly examine student preferences for PAL compared to interactions with their clinical instructors. This section will overview student preferences for peer teaching and learning, peer assessment and feedback, peer mentoring, and peer leadership as substantiated in the medical, nursing, physical therapy, and to some extent, the athletic training literature. As well, areas for further research in athletic training clinical education regarding student preferences for PAL will be identified.

\section{Peer Teaching and Learning}

Medical students who engaged in peer teaching and learning reported mixed perspectives on their preferences for peer teaching. One study reported that students in the role of peer teacher felt they understood information better when they taught clinical concepts than when clinical concepts were taught by clinical instructors. 18 
However, students felt their understanding of clinical concepts was better when taught by clinical instructors. ${ }^{18}$ In addition, this same research indicated that medical students felt peer teaching and learning was more active, but it seemed incomplete and/or lacked sufficient detail. In another study with medical students, faculty perceived that their presence during standardized patient evaluations adversely affected student confidence and performance. These perceptions would seem to imply that students may prefer peer interactions because they are more confident performing skills in front of their peers.

Nursing students also report mixed perspectives on their preferences for peer teaching compared to clinical instructors. Researchers compared cognitive and psychomotor test scores in nursing students who received primarily peer instruction to those who received instruction from a nursing clinical instructor. ${ }^{10}$ Students who received peer instruction had significantly higher cognitive test scores and moderately higher psychomotor test scores than those who received instruction from a clinical instructor. However, students were undecided as to whether they preferred one type of instructor over the other. ${ }^{10}$

In contrast to medical and nursing students, physical therapy students appear to prefer instruction from their clinical instructors over instruction from their peers. ${ }^{11}$ Students involved in a clinical experience with a 2:1 student to clinical instructor ratio reported a need for more one-on-one time with their clinical instructor. Further, they did not prefer to receive feedback in a group. ${ }^{11}$ However, physical therapy researchers indicate that most clinical instructors perceived that while a clinical rotation with a $2: 1$ student to clinical instructor ratio is conducive for peer teaching, the $2: 1$ ratio was harder for the clinical instructors to manage. This was due to the students' differing levels of previous clinical experience or knowledge. ${ }^{22}$

Previous research regarding peer teaching in athletic training demonstrates that students have some preference for a peer teacher over a clinical instructor. Athletic training students preferred clinical education that was collaborative in nature as they felt less anxious performing psychomotor skills in the presence of a peer than with a clinical instructor. ${ }^{2,12}$ Further research is necessary to determine if athletic training students prefer planned or unplanned PAL in various settings. In addition, preferences for peer teaching and learning may be affected by the academic/experience level of the peer teacher and learner, warranting investigation.

\section{Peer Assessment and Feedback}

Little research has examined student preferences for peer assessment and feedback. Nursing students reported feeling more at ease when being observed and evaluated by their peers compared to being observed and evaluated by their clinical instructors. ${ }^{24}$ Recent research in athletic training clinical education indicates that students have mixed perspectives on preferences for peer feedback. ${ }^{2,12}$ One study indicates that athletic training students do not perceive the feedback they received from their peers to be more helpful than the feedback received from their clinical instructors. ${ }^{2}$
However, a more recent study indicates that students are undecided as to whether peer feedback is more helpful. ${ }^{12}$ Feedback from both peers and clinical instructors may impact the professional development of the student. Therefore, it would be helpful to determine if there are instances when athletic training students prefer peer assessment and feedback over clinical instructor assessment and feedback. In conjunction, the reliability and validity of peer assessment in athletic training is unknown and would be helpful in determining the appropriateness of implementing this form of PAL in clinical education.

\section{Summary of Research Needed Regarding Preferences for PAL in} Athletic Training

Athletic training clinical education research is largely inconclusive on student preferences for peer teaching and learning, and peer assessment and feedback. In addition, there appear to be no studies that examine student preferences for peer mentoring or peer leadership. Therefore, the following research questions warrant further study:

1. Are some clinical settings more appropriate than others for implementing PAL?

2. Do students prefer PAL in some situations (e.g., practicing clinical skills) and not in others (e.g., seeking career advice)?

\section{Conclusions}

PAL has not only been demonstrated to reduce demands on clinical instructors, but also to improve the overall clinical experiences for students. ${ }^{13}$ PAL should not replace the roles of the clinical instructor regarding assessment, teaching, mentoring, and leadership. ${ }^{2}$ Rather, PAL should be used to supplement and augment the clinical instructor. ${ }^{12}$ Students involved in PAL should derive mutual benefits whether the student is the teacher or the learner. ${ }^{17}$

Further research on PAL in athletic training is necessary. Research is warranted regarding the occurrence of planned and unplanned PAL from the perspective of program administrators, faculty, clinical instructors, and students. These multiple perspectives will allow for a more complete understanding of the frequency of PAL in athletic training clinical education. With this understanding, the groundwork will be in place for future studies comparing student's learning outcomes in ATEPs with planned PAL to those with unplanned PAL.

Whether athletic training students benefit from various types of PAL such as peer mentoring and peer leadership is unclear. Certainly, PAL cannot be viewed as a panacea for improving all aspects of clinical education. However, the health professions literature clearly supports the notion that PAL can be a useful clinical education tool. Therefore, it is essential to determine whether athletic training students prefer PAL in some situations (e.g., practicing clinical skills) and not in others (e.g., seeking career advice). Furthermore, the validity and reliability of peer assessment needs to be established in athletic training clinical education to 
ensure that the students benefit from peer assessment activities. Once we have addressed these issues and others that arise, the value of PAL as a tool in AT education can be understood and the appropriate use of PAL can be implemented.

\section{References}

1. Weidner TG, Henning JM. Importance and applicability of approved clinical instructor standards. J Athl Train. 2005;40:326-332.

2. Henning JM, Weidner TG, Jones J. Peer-assisted learning in the athletic training clinical setting. J Athl Train. 2006;41:102-108.

3. Costello J. Learning from each other: peer teaching and learning in student nurse training. Nurse Educ Today. 1989;9:203-206.

4. Mensch JM, Ennis CD. Pedagogic strategies perceived to enhance student learning in athletic training education. J Athl Train. 2002;37:S-199-S-207.

5. Aston L, Molassiotis A. Supervising and supporting student nurses in clinical placement: the peer support initiative. Nurse Educ Today. 2003;23:202-210.

6. Aviram M, Ophir R, Raviv D, Shiloah M. Experiential learning of clinical skills by beginning nursing students: "coaching" project by fourth-year student interns. J Nurs Educ. 1998;37:228-231.

7. Escovitz ES. Using senior students as clinical skills teaching assistants. Acad Med. 1990;65:733-734.

8. Scott ES. Peer-to-peer mentoring: teaching collegiality. Nurse Educ. 2005;30:52-56.

9. Yates P, Cunningham J, Moyle W, Wollin J. Peer mentorship in clinical education: outcomes of a pilot programme for first year students. Nurse Educ Today. 1997;17:508-514.

10. Iwasiw CL, Goldenberg D. Peer teaching among nursing students in the clinical area: effects on student learning. $J A d v$ Nurs. 1993;18:659-668.

11. Triggs Nemshick M, Shepard KF, Ladyshewsky R. Physical therapy clinical education in a 2:1 student-instructor education model. Phys Ther. 1996;76:968-984.

12. Weidner TG, Popp JK. Peer assisted learning is effective in improving orthopedic evaluation psychomotor skills. $J$ Athl Train. 2007;42:113-119.

13. Ammon K, Schroll NM. The junior student as peer leader. Nurs Outlook. 1988;36:85-86.

14. Bos S. Perceived benefits of peer leadership as described by junior baccalaureate nursing students. J Nurs Educ. 1998;37:189-191.

15. Burnside IM. Peer supervision: a method of teaching. J Nurs Educ. 1971;10:15-22.

16. Glass N, Walter R. An experience of peer mentoring with student nurses: enhancement of personal and professional growth. $J$ Nurs Educ. 2000;39:155- 160.

17. Topping K, Ehly SW, eds. Peer-Assisted Learning. Mahway, NJ: Lawrence Erlbaum Associates; 1998.

18. Hendelman WJ. Reciprocal peer teaching by medical students in the gross anatomy laboratory. J Med Educ. 1986;61:674-680.

19. Cason CL, Cason GJ, Bartnik DA. Peer instruction in professional nurse education: a qualitative case study. $J$ Nurs Educ. 1977;16:10-22.

20. Lewin DC, Leach J. Factors influencing the quality of wards as learning environments for student nurses. Int $J$ Nurs Stud. 1982;19:125-137.

21. DeClute J, Ladyshewsky R, Deusinger MJ, Emery MJ, Gandy JS. Enhancing clinical competence using a collaborative clinical education model. Phys Ther. 1993;73:683-697.

22. Ladyshewsky R. Clinical teaching and the 2:1 student-to-clinical instructor ratio. $J$ Phys Ther Educ. 1993;7:31-35.

23. Emery MJ, Nalette E. Student-staffed clinics: creative clinical education during times of constraint. Clin Manag Phys Ther. 1986;6:6, 9-10.

24. Erickson GP. Peer evaluation as a teaching-learning strategy in baccalaureate education for community health nursing. J Nurs Educ. 1987;26:204-206.

25. Flynn JP, Marcus MT, Schmadl JC. Peer review: a successful teaching strategy in baccalaureate education. $J$ Nurs Educ. 1981;23:28-32.

26. Arnold L, Shue CK, Kritt B, Ginsburg S, Stern DT. Medical students' views on peer assessment of professionalism. $J$ Gen Intern Med. 2005;20:819-824.

27. Calhoun JG, Woolliscroft JO, Ten Haken JD, Wolf FM, Davis WK. Evaluating medical student clinical performance: relationships among self, peer and expert ratings. Eval Health Prof. 1988;11:201-212.

28. Rudy DW, Fejfar MC, Griffith III CH, Wilson JF. Self- and peer assessment in a first-year communications and interviewing course. Eval Health Prof. 2001;24:436-445.

29. Walsh K, Kugler K, J B. Assessment: taking the "exam" out of evaluation. Athl Ther Today. 2003;8:21-26.

30. Henning JM, Marty MC. A practical guide to implementing peer assessment in athletic training education. Athl Ther Today.2008;13:29-32 .

31. Pitney WA, Ehlers G, Walker S. A descriptive study of athletic training students' perceptions of effective mentoring. Internet J Allied Health Science Practice. 2006;4:1-8.

32. McPherson BD. Socialization into and through sport involvement. In: Luschen GRF, Sage GH, eds. Handbook of Social Science of Sport. Champaign, IL: Stipes; 1981:246-273.

33. Vaidya SR. Improving teaching and learning through peer coaching. Education. 1994;115:241-245.

34. Glynn LG, MacFarlane A, Kelly M, Cantillon P, Murphy AW. Helping each other to learn- a process evaluation of peer assisted learning. BMC Med Educ. 2006;6:18.

35. Kushnir T. Stress and social facilitation: the effects of the presence of an instructor on student nurses' behavior. $J$ Adv Nurs. 1986;11:13-19.

36. Ladyshewsky R, Healey E. The 2:1 Teaching Model in Clinical Education. Toronto, Canada: University of Toronto; 1990.

37. Topping K. Peer assessment between students in colleges and universities. Rev Educ Res. 1998;68:249-276.

38. Gerace L, Sibilano H. Preparing students for peer collaboration: a clinical teaching model. J Nurs Educ. 2006;23:206-209.

39. Ladyshewsky R, Gotjamanos E. Communication skill development in health professional education: the use of standardized patients in combination with a peer assessment strategy. J Allied Health. 1997;26:177-186.

40. Amato H, Hawkins C, Cole S. Clinical Skills Documentation Guide for Athletic Training. 2nd ed. Thorofare, NJ: SLACK Incorporated; 2006.

41. Knight K. Assessing Clinical Proficiencies in Athletic Training: A Modular Approach. 3rd ed. Champaign, IL: Human Kinetics; 2001. 